\title{
Habitat suitability model of endangered Latidens salimalii and the probable consequences of global warming
}

\author{
Sreehari Raman ${ }^{1,2,3} \cdot$ Thekke Thumbath Shameer $^{4}$ (1) $\cdot$ Bipin Charles $^{5} \cdot$ Raveendranathanpillai Sanil $^{4}$
}

Received: 18 April 2020 / Revised: 20 September 2020 / Accepted: 27 September 2020 / Published online: 7 October 2020

(C) International Society for Tropical Ecology 2020

\begin{abstract}
Salim Ali's fruit bat, Latidens salimalii, is a monotypic endangered fruit bat endemic to Western Ghats (WG) with an ambiguous distribution. The distribution range, habitat suitability, and biology of this species are still uncertain. Endemic species inhabiting the high elevation of WG like $L$. salimalii are threatened due to climatic change and seeks urgent management interventions. Hence, we developed a habitat suitability model for $L$. salimalii using MaxEnt in the current climate condition and projected their distribution for three Representation Concentration Pathway (RCP 4.5, 6.0, and 8.5) climate scenarios of the 2070 time frame. The results show that $9531 \mathrm{~km}^{2}$ of habitat in WG is suitable for $L$. salimalii at present, while all the future scenarios estimates propose complete loss of highly suitable habitat. The significant factors influencing the distribution of L. salimalii are the precipitation of the driest month, tree density, rain in the coldest quarter, canopy height, and altitude. The study pioneers in predicting the suitable habitat and emphasis the need to develop strategies for the long-term conservation of endangered $L$. salimalii in WG under global warming scenarios.
\end{abstract}

Keywords Climate change $\cdot$ Endemic species $\cdot$ Habitat loss $\cdot$ Maxent $\cdot$ Western Ghats

Electronic supplementary material The online version of this article (https://doi.org/10.1007/s42965-020-00114-5) contains supplementary material, which is available to authorized users.

Thekke Thumbath Shameer

shameerh4u@yahoo.com

1 Center for Integrative Conservation, Xishuangbanna Tropical Botanical Garden, Chinese Academy of Sciences, Menglun, Mengla, Yunnan, Beijing 666303, China

2 University of Chinese Academy of Sciences, Beijing 100049, China

3 Department of Wildlife Science, College of Forestry, Kerala Agricultural University, Vellanikkara, 680656 Thrissur, Kerala, India

4 Molecular Biodiversity Lab, Department of Zoology and Wildlife Biology, Government Arts College, The Nilgiris, Udhagamandalam, Tamil Nadu 643002, India

5 Institute for Biodiversity Conservation and Training, \#5, 7th Main Road, Shankar Nagar, Bangalore, Karnataka 560096, India

\section{Introduction}

Bats are a highly threatened group of mammals fronting population drop owing to several reasons. These keystone species play a pivotal role in the modulating ecosystem in which they live. They are responsible for pollination and long-distance dispersal of seeds and fruits, by which it influences the lifecycle of tropical plants (Castaño et al. 2018). Reducing the abundance of such vital species can lead to diminished seed dispersal and pollination, thereby upsetting the complete balance of the ecosystem dynamics (Mokany et al. 2013; Castaño et al. 2018). Bats face massive perils due to emerging diseases, depletion of the habitat, hazardous effects of pesticides, and timber harvesting. The endemic Salim Ali's fruit bat Latidens salimalii Thonglongya (1972), is a critically endangered nocturnal animal distributed above an altitude of 800 MSL (Molur and Vanitharani 2008) in the Western Ghats (WG). Approximately, 1200 individuals of the species are only cited by different authors from various localities in Southern WG (Thonglongya 1972; Bates and Harrison 1997; Ghosh et al. 1999; Vanitharani et al. 2004; Agoramoorthy and Hsu 2005; Wordley et al. 2016; Joy et al. 2019). 
Latidens salimalii is a monotypic genus and a protected schedule I animal by the Indian Wildlife Protection act. The distribution range of the bat is from Meghamalai (Bates et al. 1994; Muni 1994; Singaravelan and Marimuthu 2003a; Agoramoorthy and Hsu 2005), Kalakkad-Mundanthurai Tiger Reserve (Ghosh et al. 1999; Vanitharani et al. 2004), Courtallum Hills in Tirunelveli (Vanitharani et al. 2004), Valparai (Wordley et al. 2016), and Mankulam forest division (Joy et al. 2019). There are unpublished sightings of L. salimalii from Meghamalai (Tamil Nadu), Periyar Tiger Reserve (Kerala), and Uppinangady (Karnataka), but the definite distribution range is still indistinct. Body size is medium; an adult bat is approximately $10 \mathrm{~cm}$ in length and $64 \mathrm{~g}$ in weight, having round-tipped oval ears and without an external tail. The dorsal pelage is dark brown to grizzled black with soft and dense pale hairs, and the patagium is without coats, and the baculum is massive. Unlike other fruit bats, they have only one pair of upper and lower incisors. The narrow rostrum and braincase are elongated, and the small first premolar slightly exceeds the crown area (Bates et al. 1994; Bates and Harrison 1997; Vanitharani et al. 2004). They roosts predominantly in caves (Singaravelan and Marimuthu 2003a) and abandoned buildings (Vanitharani et al. 2004). The feeding ecology of this bat species is undefined; few incidental observations (Singaravelan and Marimuthu 2003a; Vanitharani et al. 2004; Agoramoorthy and Hsu 2005) show that they feed on Prunus, Ficus, Elaeocarpus, Diospyros, and Dichapetalum.

Climate change is the prime reason for the modification and elimination of endemic fauna with constrained distribution and limited population size. Climate change has an intense effect on sustaining the indigenous vegetation of a locality, thereby directly associated with the survival of endemic fauna (Gopalakrishan et al. 2011). The very dynamic demand that the conservationist address is 'how to formulate suitable strategies' to combat the changing global warming scenario (Chapman et al. 2005). It can be challenging when the species under consideration is a critically endangered monotypic macro-chiropteran with inadequate records and ecology (Vanitharani et al. 2004; Wordley et al. 2016). Many factors may regulate the endemism of a volant species towards a specified climate range in the high altitudes of WG. The elements can be a physiological or floral dependency, or the species can be a relic of an evolutionary lineage of climate specialists. In such a case of an endemic species with inadequate knowledge of natural history, it is appropriate to develop digital habitat models based on the available information.

The study targeted comprehending vulnerable regions and critical habitats of $L$. salimalii under climatic and other physiographic factors. As an endangered endemic species of the WG, the understanding of habitat loss is a direct assessment of the landscape. We designed our study as an attempt to (a) to recognize the suitable habitats of $L$. salimalii using occurrence information concerning environmental variables, and (b) to foresee the effect of climate change on the potential distribution of this species for three future climate scenarios (RCP 4.5, RCP 6.0 and RCP 8.5), (c) and to distinguish the zones that to be secured for the long term protection of the species using maximum entropy model (MaxEnt).

\section{Methodology}

\section{Study locale}

The WG is an extraordinarily delicate assorted ecosystem accommodating rich endemic and imperilled flora and fauna, making it a hotspot of diversity (Cincotta et al. 2000; Myers et al. 2000). The $1600 \mathrm{~km}$ long mountain chain on the west coast of peninsular India is unique owing to diverse topography, varying altitude, diverging climate, and an array of habitats. Humid tropical conditions prevail in the lower elevations, while the temperate climate is predominant in the upper reaches with an annual average temperature of $15{ }^{\circ} \mathrm{C}$. The WG receives both the Northeast and Southwest monsoon and receives the average rainfall of $300-400 \mathrm{~cm}$. In the present scenario, the WG is confronting severe threats from the developmental activities, deforestation, forest encroachment, infra-structure developmental actions, agricultural expansion, hydro-electric projects, mining, timber logging, forest product extraction, and other human-induced stress (Menon and Bawa 1997; Priti et al. 2016; Sen et al. 2016; Sony et al. 2018; Raman et al. 2020). Identical to other tropical montane ecosystems, WG is in a rapid transforming stage, but the exact pace and form are poorly understood. The deviations in the land use and land cover pattern have a strong influence on this fragile ecosystem (Sukumar et al. 1995; Menon and Bawa 1997). The habitat alteration for human needs, unempirical tourism projects, and the spread of exotic or invasive species already drove many species to extinction. The diminution of shola-grasslands and replacement with exotics dominates the landscape modification with erratic backlashes.

\section{Occurrence records}

We conducted an in-depth survey on the western slopes of the Southern WG to assess the presence of $L$. salimalii. The survey sampled 38 locations across the southern slopes to determine the presence of this species during 2017-2018. In 2019, we repeated the sampling of L. salimalii along with the Kerala Forest and Wildlife Department in selected protected reserves. A four-shelved mistnet of $38 \mathrm{~mm}$ mesh size is placed in the sampling localities to monitor the bats following the protocols of Sikes and 
Gannon (2011). Morphometric measurements and the taxonomic features identified/photographs and the individuals were released immediately. We followed the descriptions of Bates et al. (1994), Bates and Harrison (1997), and Vanitharani et al. (2004) to identify L. salimalii. Location coordinates were archived using Garmin etrex e20 GPS. The coordinates of the published and unpublished data (Thonglongya 1972; Bates et al. 1994; Muni 1994; Ghosh et al. 1999; Easa et al. 2001; Molur et al. 2002; Singaravelan and Marimuthu 2003a, b; Vanitharani et al. 2004; Agoramoorthy and Hsu 2005; Molur and Vanitharani 2008; Babu et al. 2013; Wordley et al. 2016; Joy et al. 2019) were also collected and geo-referenced using the Google Earth. We compiled 69 records from our survey and other published records (Supplementary table S1). The spatial autocorrelation between the sightings of $L$. salimalii was rectified by thinning using the package "spThin" (AielloLammens et al. 2015) in the R platform. We eliminated the spatially auto-correlated incidence points and tumbling the multiple occurrences, and reduced the incidence records to 16 from 69 (Fig. 1).

\section{Environmental variables}

We used the tree density, canopy height, elevation, and the nineteen bioclimatic variables as the predictor variables for distribution modeling. We downloaded the elevation layer from the NOAA website (https://www.ngdc.noaa. gov/mgg/topo/globe.html), the tree density from Crowther et al. (2015), global forest canopy heights from Simard et al. (2011), and the 19 bioclimatic predictor variables from the Worldclim database (https://www.worldclim.org) at $1 \mathrm{~km}$ scale. We selected only the variables having limited effects on the $L$. salimalii predictive models to get an optimum predictive model with reduced masking effects. Veloz (2009) reported that even mildly correlated layers could influence the precision of species distribution models. Hence we choose the final set of the environmental variable after accounting for multi-collinearity to generate a model with high accuracy. We finalised seven variables for the Habitat suitability modeling (HSM) by estimating the variance inflation factors (VIFs) in R package "usdm" (Naimi 2013), ignoring the variables scored higher than 5 (VIFs $>5$ ). We used the bio3 (isothermality), bio14 (precipitation of driest month), bio18 (precipitation of warmest quarter), and bio19 (precipitation of coldest quarter), one topographic layer (altitude), and two vegetation layers (tree density and canopy height) to develop habitat suitability models. bio3 (isothermality) is (bio2/bio7 $\times 100$ ) in which bio $2=$ mean diurnal range (mean of monthly ( $\max$ temp $-\min$ temp)), bio7 $=$ temperature annual range.

\section{Modeling and corroboration}

MaxEnt software Version 3.3.3k (Phillips et al. 2006) works on the maximum-entropy is used to develop the habitat suitability model of $L$. salimalii. This model also has proven its efficiency in monitoring bats in high elevation ranges (Debata et al. 2019). The software uses environment variables and geo-referenced localities to predict log transformations or raw exponential outputs. The models having maximum entropy is the best model, subjected to certain constraints. MaxEnt is used universally as the preferred modeling choice for the extrapolation of species distribution with high precision (Bosso et al. 2018; Soucy et al. 2018; Zhang et al. 2018). The software initiates running, assuming a uniform distribution, and performs continuous iterations, which increases the suitable location possibility (Merow et al. 2013). We identified all the selected seven variables to run the model as continuous variables. The logistic output was used, which is the estimated probability of the binary argument of a species based on the given environmental variables (Merow et al. 2013). Logistic output also permits us to make a dissimilarity between the appropriateness of different areas.

We adjusted the existing models by shifting the regularization multiplier (rm) values. We transformed the model complexity by changing different feature types like linear $(\mathrm{L})$, product $(\mathrm{P})$, quadratic $(\mathrm{Q})$, and hinge $(\mathrm{H})$. Using the "ENMeval" (Muscarella et al. 2014) package in R platform, we developed forty-eight (48) models with varying levels of complexity and different regularization multiplier values. Among the developed models, the best fit model was chosen based on the lowest corrected Akaike Index Criterion (L-Q and $\mathrm{rm} \mathrm{0.5)} \mathrm{for} \mathrm{the} \mathrm{current} \mathrm{habitat} \mathrm{modeling} \mathrm{(Supplemen-}$ tary Table 2). We generated a bias grid using the R package "KernSmooth" (Wand, 1994) by calculating the Gaussian kernel density of sampling localities, considering the potential bias in sampling location data. We run the model for L. salimalii with 5000 iterations, and 16 replicates with a subsampling procedure, among which $20 \%$ of iterations were for training, and the remaining $(80 \%)$ was for testing. The significance of the contribution of all the seven environmental variables was estimated using the Jackknife protocol. We mapped the Maxent outputs using the geographic information system application QGIS ver 3.14.15. The EOO (Extent of Occurrence) of $L$. salimalii was determined using the software GeoCAT (https://geocat.kew.org). The change in suitable habitats under future climatic conditions was estimated using DIVA-GIS (https://www.diva-gis.org).

\section{Habitat alteration forecasting in the climate change scenario}

The future climatic projections were derived using the bioclimatic variables for three Representative Concentration 


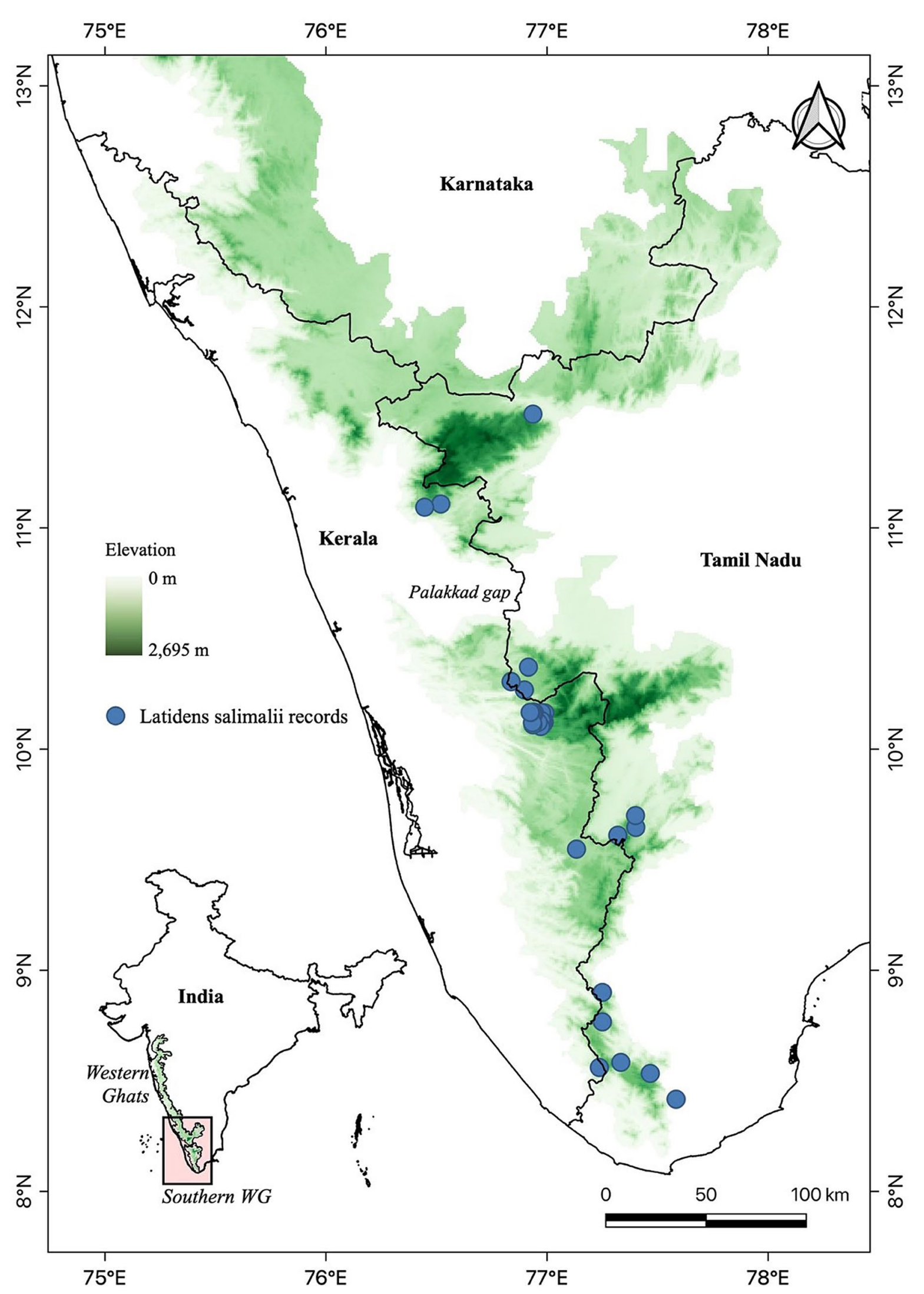

Fig. 1 Locations of Latidens salimalii in the WG mountain chains in India 
Pathways (RCP 4.5, RCP 6.0, and RCP 8.5). We followed the Hadley Global Environment Model 2-Atmosphere Ocean (HADGEM2-AO) of 30 arc-second ( $1 \mathrm{~km})$ spatial resolution, as presented in the fifth assessment report (AR5) of the Intergovernmental Panel for Climate Change (IPCC 2014). RCP 4.5 represents an optimistic emission scenario, where emissions will peak around 2040 and then decline. RCP 6.0 is also a stabilizing emission scenario where the emission will get stabilized after the 2060s. RCP 8.5 assumes increased greenhouse gas emissions throughout the twentyfirst century (Sharma et al. 2017). Projections are made up to 2070 in the WG region using the future climatic variables downloaded from the Consultative Group on International Agricultural Research's (CGIAR) Research Program on Climate Change, Agriculture and Food Security (CCAFS) climate data archive (https://www.ccafs-climate.org/data). We treated the topographic features for future projection as static and dynamic non-climatic variables are expected to change in the future (ex. vegetation cover) were omitted from this analysis.

\section{Model appraisal}

Two metrics, the area under receiver operating characteristic curve (AUC) and the true skill statistics (TSS), were used for model appraisal. AUC is a threshold-independent metric that measures the model's ability to distinguish between random and background points to evaluate the model performances. A high AUC score does not always reflect that the models are highly informative (Phillips et al. 2006), and the evaluation based on the AUC score alone is not reliable (Austin 2007; Lobo et al. 2008). Hence, we also estimated the TSS scores, which is a threshold dependent measure of accuracy. The formula sensitivity + specificity -1 is used to calculate TSS, where sensitivity and specificity are measured based on the probability threshold for which their sum is maximized (Allouche et al. 2006).

\section{Results}

We recorded $L$. salimalii from the Thondiyar of Periyar Tiger Reserve (PTR) and Silent Valley National Park (SVNP). Our identification is the pioneering one establishing endangered $L$. salimalii from PTR and SVNP (Fig. 2). The observation extends the range of $L$. salimalii towards the north of Palghat gap. The morphometric measurements of the specimen observed from these reserves and the first specimen from the High Wavy Mountains remain almost similar (Table 1).
Fig. 2 Portrait of Latidens salimalii (a), ventral view (b), dorsal view (c), lower jaw with one pair of incisor $(\mathbf{d})$

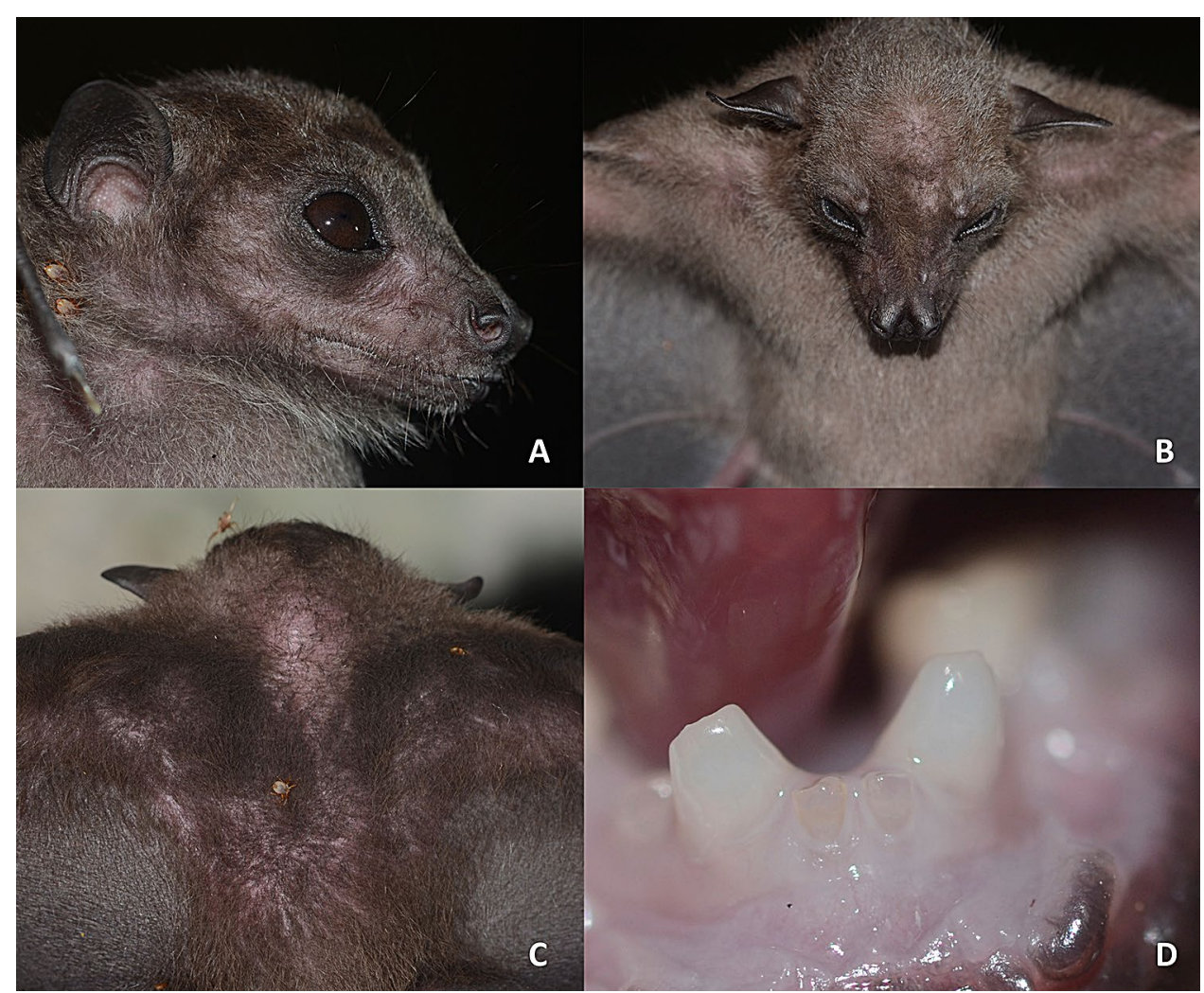


Table 1 External measurements (mm) of L. salimalii recorded from Periyar Tiger Reserve and Silent Valley National Park in WG

\begin{tabular}{lccl}
\hline Measurements & $\begin{array}{l}\text { Periyar Tiger } \\
\text { Reserve }\end{array}$ & $\begin{array}{l}\text { Silent Valley } \\
\text { National Park }\end{array}$ & $\begin{array}{l}\text { Bates and } \\
\text { Harrison } \\
(1997)\end{array}$ \\
\hline Forearm length & 69.3 & 70.2 & 67.3 \\
Head-body length & 111.8 & 108.7 & 106.7 \\
Ear & 17.8 & 17.1 & 16.8 \\
Tibia & 33.1 & 32.3 & NA \\
Hind foot & 13.2 & 13.1 & 13.4 \\
Third metacarpal & 48.3 & 47.9 & 47.4 \\
Fourth metacarpal & 44.5 & 43.9 & 45.4 \\
Fifth metacarpal & 46.7 & 44.7 & 45.1 \\
\hline
\end{tabular}

\section{Model performance}

The model performance was evaluated based on the AUC and TSS values. The best performing model had an average AUC of 0.95 and a TSS value of 0.80 . The accuracy of the predicted model is 0.80 , the sensitivity is 1 , and the specificity is 0.80 . These values indicate that the model performed well in predicting suitable habitat of $L$. salimalii in the WG region of peninsular India.

\section{Important environmental variables}

From the seven environmental variables, the most significant variable identified to influence the spatial distribution of $L$. salimalii is the precipitation of the driest month (58.6\%), tree density (34\%), elevation (3.4\%), and the rainfall of the coldest quarter (3.2\%). The cumulative contribution of these variables is $99.2 \%$. These variables form the factors responsible for the highest permutation importance settling their most tremendous significance in the final model (Table 2). The Jackknifing protocol indicates that these variables significantly contribute to the predicted model compared to the other variables (Fig. 3). The logistic output (interpreted as portability of presence) of $L$. salimalii peaked towards the higher value of the variables altitude, bio14, bio18, bio3, and tree density. The other variable, like bio 19 and canopy height, indicated a negative influence of species distribution with increasing values. It clarifies that the preferred vegetation type by $L$. salimalii is short, stunted montane one than the tall trees in the lower tropical climate. Similarly, the local storms in the unexpected seasons other than the traditional monsoon are also not favourable for survival.

\section{Currently suitable habitat of $L$. salimalii}

The current model revealed that the regions having appropriate and optimal environmental conditions for the species lie mostly in the southern WG, especially to the south
Table 2 Contribution percentage and permutation importance of correlated environmental variables used for HSM

\begin{tabular}{lll}
\hline Variable & $\begin{array}{l}\text { Percent } \\
\text { contribu- } \\
\text { tion }\end{array}$ & $\begin{array}{l}\text { Permutation } \\
\text { importance }\end{array}$ \\
\hline $\begin{array}{l}\text { bio_14 [precipitation of driest } \\
\text { month(mm)] }\end{array}$ & 58.6 & 37.5 \\
$\begin{array}{l}\text { Tree_density } \\
\text { Altitude }\end{array}$ & 34 & 29.5 \\
bio_19 [precipitation of coldest quarter & 3.4 & 10.3 \\
$\quad$ (mm)] & 3.2 & 19.8 \\
Canopy_height & 0.4 & 1.2 \\
bio_3 (isothermality) & 0.3 & 1.5 \\
bio_18 [precipitation of warmest & 0.1 & 0.1 \\
$\quad$ quarter(mm)] & & \\
\hline
\end{tabular}

of the Palghat gap (Fig. 4). The Mukurthi National Park, Silent Valley National Park, Indira Gandhi (Anamalai) Tiger Reserve (TR), Eravikulam National Park, Pamadum shola National Park, Anamudishola National Park, Mathikettanshola National Park, Periyar Tiger Reserve, Shenduruny Wildlife Sanctuary, and Kalakkad Mundanthurai Tiger Reserve are highly suitable habitat for survival and reproduction of $L$. salimalii under the current scenario. Overall potential distribution areas of $L$. salimalii in WG are estimated to be $21,089 \mathrm{~km}^{2}$, which are found higher than the EOO $\left(17,183.13 \mathrm{~km}^{2}\right)$. Of this total suitable area, $9531 \mathrm{~km}^{2}$ (45.19\%) has a very high potential as the critical habitat of L. salimalii (Table 3 ).

\section{Changes in habitat suitability and loss in protected areas}

We estimated the future changes in potential habitat by taking the difference between the areas under current and future distribution (Table 3). The model predictions under the RCP 4.5, RCP 6.0, and RCP 8.5 scenarios for the 2070 time frame revealed that the areas currently identified as suitable would become increasingly unsuitable for $L$. salimalii by 2070 (Fig. 5). The relatively optimistic climate change scenario (RCP 4.5) predicted a decline of high and very-high potential areas likely by $81.30 \%$ and $99.78 \%$, respectively. The extreme climate change scenario RCP 8.5 predicted the maximum range loss of high potential areas $(99.57 \%)$ and high potential (100\%). The Mukurthi National Park, Silent Valley National Park, Anamalai Tiger Reserve (ATR), Eravikulam National Park, Mathikettan shola National Park, Pamadum shola National Park, Anamudi shola National Park, Manjapetti (ATR), Idukki Wildlife Sanctuary, Srivilliputhur Wildlife Sanctuary, Periyar Tiger Reserve, Shenduruny Wildlife Sanctuary, Peppara Wildlife Sanctuary, Neyyar Wildlife Sanctuary, and Kalakkad Mundanthurai 

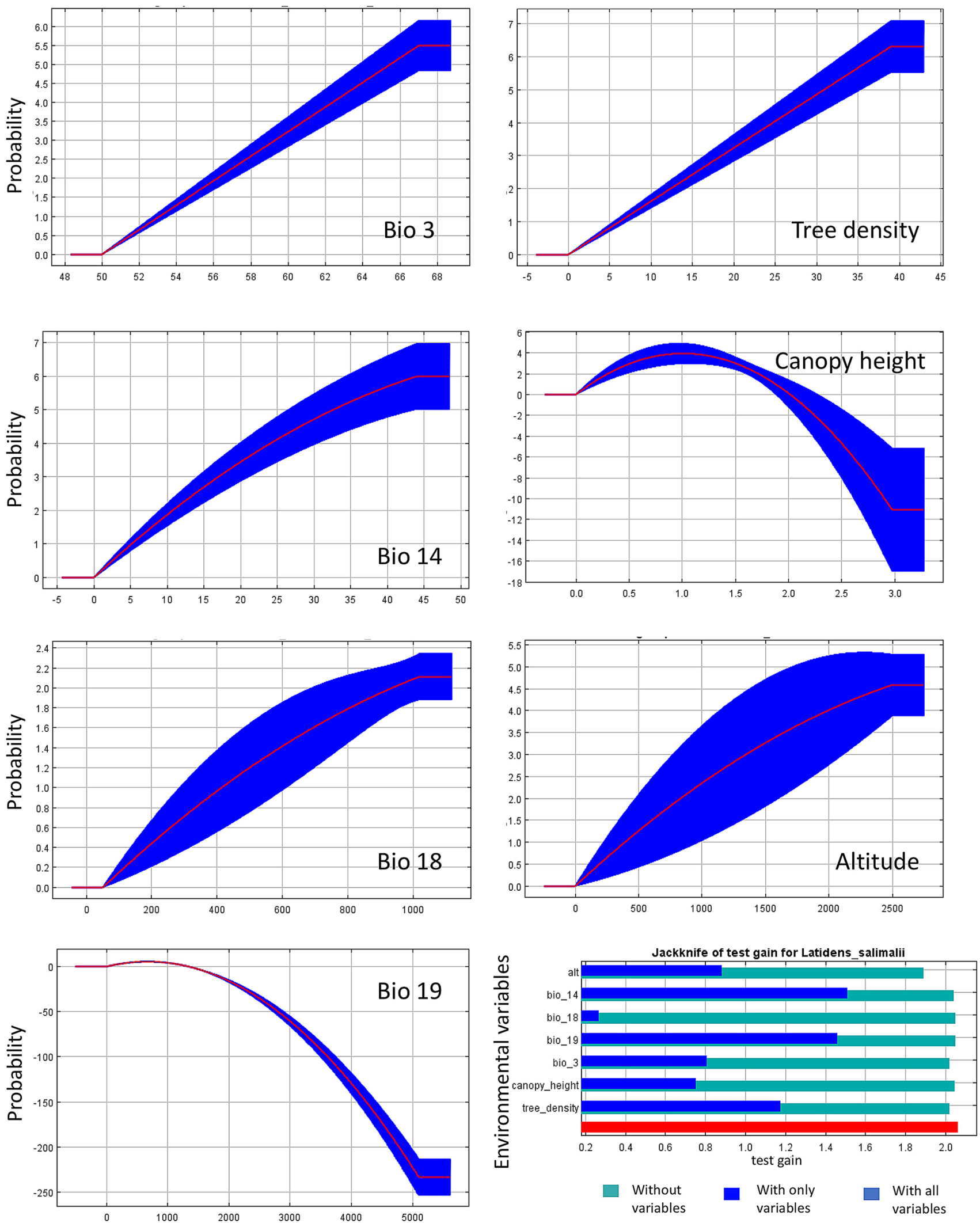

Fig. 3 Response curves showing relationships between the important environmental variables and probability of presence of Latidens salimalii and Jackknife test showing the relative importance of different

environmental predictors. The values shown are an average of ten replicates of cross-validated Maxent models 


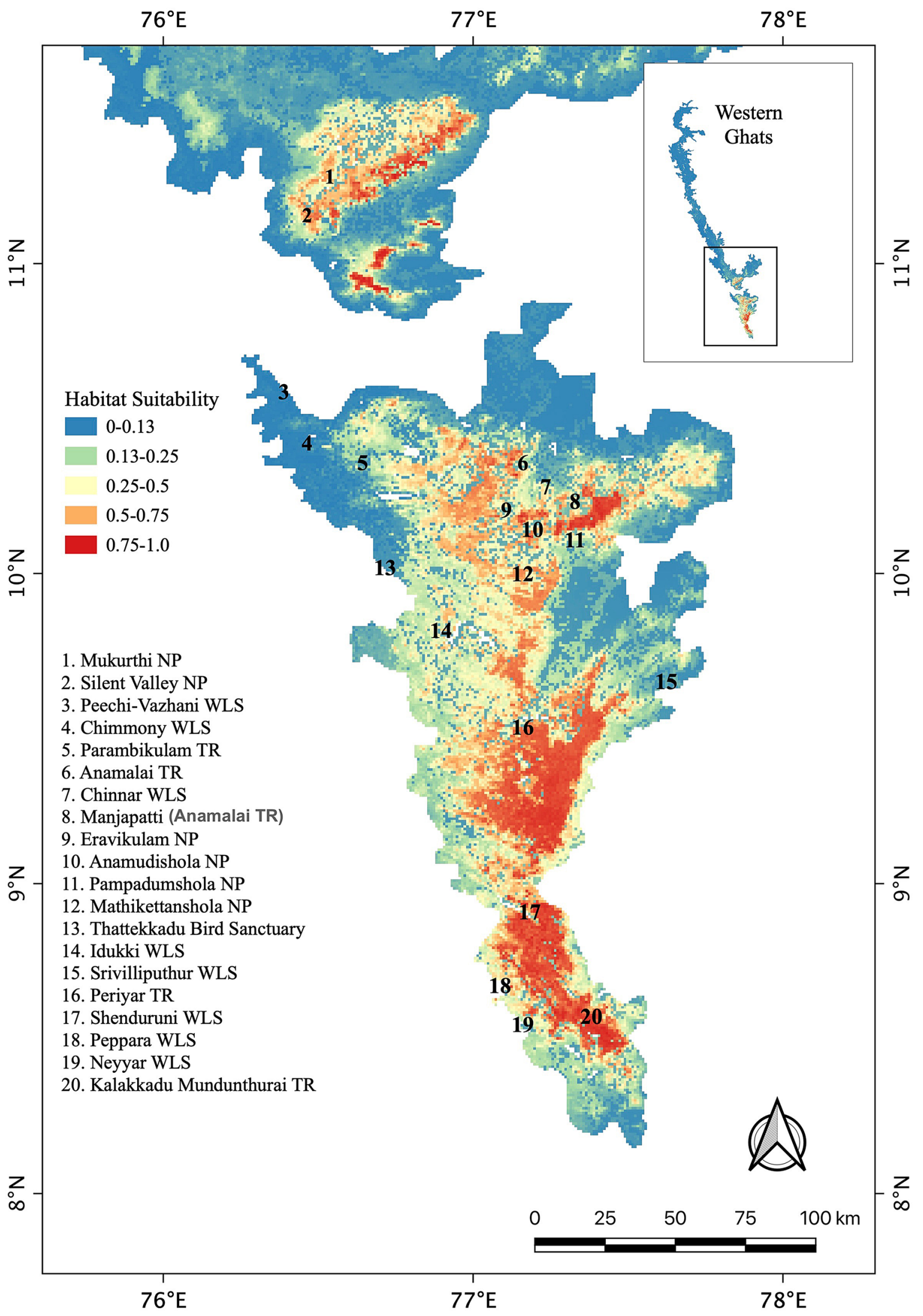

Fig. 4 Habitat suitability for L. salimalii in WG under the current climatic conditions, vegetation and topographic feature 
Tiger Reserve assessed as highly vulnerable to extreme climates. We predict the complete absence of suitable and very high suitable habitat for $L$. salimalii in the future scenario under RCP $8.5 \%$. These protected areas may experience drastic habitat loss for $L$. salimalii due to future climate modification.

\section{Discussion}

Latidens salimalii is a non-charismatic species, and the research on its ecology is rare with the actual distributive ranges remain indefinite to date. The study predicts the distribution range of $L$. salimalii on either side of the Palghat gap with more distribution towards the southern side. The distribution towards the north of the Palghat gap was a speculation, and we validated the presence from the Silent Valley National Park. The previous studies believe that the principal distribution range is towards the south of Palghat (Molur et al. 2002; Molur and Vanitharani 2008; Wordley et al. 2016). The Agastialmalai forms the core habitat of $L$. salimalii (Agoramoorthy and Hsu 2005; Molur and Vanitharani 2008), with the range extends to the Valparai plateau and Malayatoor forest division. The predictive map indicates that the suitable predicted habitat range spreads over the Nilgiris up to Karnataka. Roosting sites are primarily noted as caves and abandoned buildings inside the forested areas (Singaravelan and Marimuthu 2003a; Vanitharani et al. 2004; Agoramoorthy and Hsu 2005; Joy et al. 2019) and feed on specific floral species (Vanitharani et al. 2004; Wordley et al. 2016). The model prediction postulates the preference of the bat towards dense wooded high altitude vegetation and the specific monsoon patterns prevailing in the region. The floral structure prevailing in the unique climax community of Western Ghats is so typical with highly endemic fruit yielding evergreen and moist deciduous vegetation. The distribution of $L$. salimalii shows a negative correlation with canopy height, after an optimum range, indicates the preference towards stunted montane foliage. The studies on the structure of high altitude climax vegetation of WG (Jose et al. 1994; Bunyan et al. 2012) clearly showed that the height of the trees rarely exceed $12 \mathrm{~m}$ (stunted) and have dense canopy cover.

Debata et al. (2019) observed that the elevation and habitat act as chief determinants of chiropteran distribution, similar to our observations. The high altitudes as generally less disturbed and have rocks, crevices, and caves to provide enough space to roost and rear young ones. The trophic structure gets modified so to enable them to depend more on the native flora. The availability of food determines the biomass of folivorous and frugivorous species in a region (Chapman et al. 2005). The tree diversity in a temperate climate is comparatively fewer than in a tropical environment. The relatively lesser floral diversity creates a strong dependency between the endemic bats and native flora (Castaño et al. 2018). The changing floral pattern, according to altitudinal gradation, restricts the range of habitat specialist bats to a specific trophic structure. Global warming can kindle the range reduction of an endemic habitat specialist (Bellard et al. 2012), as the escalation of temperature, in turn, can restrict the montane climax vegetation to a short-range. The grid-based models predicted by Gopalakrishnan et al. (2011) pointed out that $77 \%$ of grids under the forest cover may face threats due the climate change shortly. Mokany et al. (2013) reported that plants with small fruits suffer long-distance seed dispersal under climate change, contributing to extensive compositional alterations in the forest flora. Our results by HSM suggest that there will be no suitable habitat of $L$. salimalii under the RCP 8.5 scenario, which could cause high extinction risk.

RameshKumar et al. (2004) predicted that the warming of the Indian sub-continent would occur shortly with an increase of temperature, both day and night. The increase in the night temperature will be more than the diurnal temperature in the coming years. Climate factors such as temperature and precipitation are strongly correlated to the biogeographical patterns of a species (Sousa-Guedes et al. 2020). The L. salimalii is influenced by rainfall and altitude, which also designates that the species is climate-dependent. In terms of precipitation in the future years, there will be an increase of unpredicted intense rainfall in WG and Peninsular India (RameshKumar et al. 2004). The anticipated increment of precipitation in the WG may seriously influence
Table 3 The predicted suitable habitat $\left(\mathrm{km}^{2}\right)$ for L. salimalii under future emission scenarios (RCP 4.5, RCP 6.0 and RCP $8.5)$

\begin{tabular}{cllll}
\hline Habitat suitability & Current & 2070 & & \\
\cline { 3 - 5 } & & RCP4.5 & RCP 6.0 & RCP 8.5 \\
\hline Least potential (0-0.13) & 112,912 & $119,363(-5.71 \%)$ & $124,822(10.55 \%)$ & $130,338(15.43)$ \\
Moderate potential (0.13-025) & 4762 & $8965(-88.26 \%)$ & $7473(56.93 \%)$ & $3207(-32.65)$ \\
Good potential (0.25-0.5) & 6796 & $5743(15.49 \%)$ & $2364(-65.21 \%)$ & $1255(-81.53 \%)$ \\
High potential (0.5-0.75) & 5037 & $942(81.30 \%)$ & $363(-92.79 \%)$ & $223(-95.57 \%)$ \\
Very-high potential (0.75-1) & 4494 & $10(99.78 \%)$ & $0(-100.00 \%)$ & $0(-100.00)$ \\
\hline
\end{tabular}




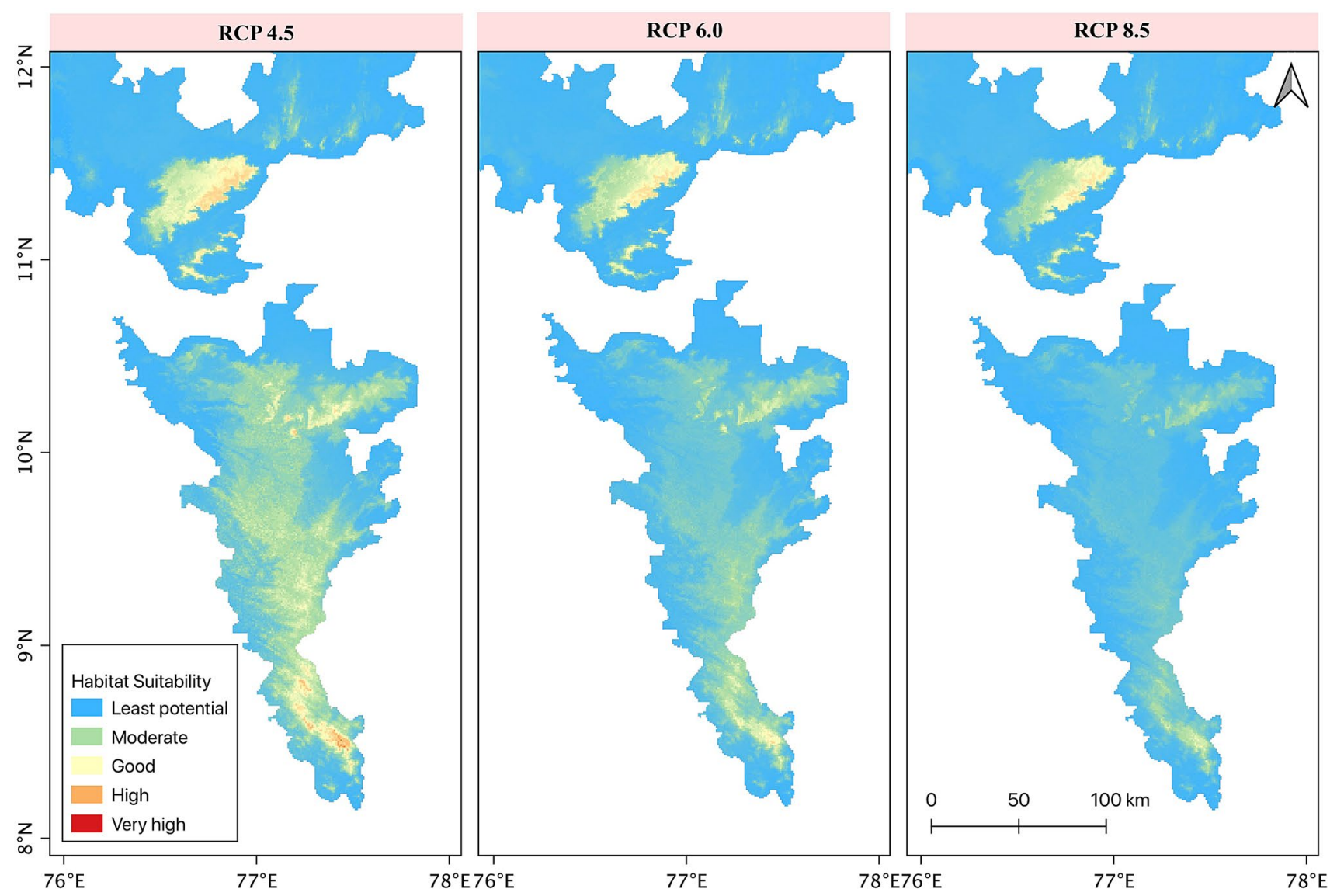

Fig. 5 Predicted future distribution model of L. salimalii under RCP 4.5 (a), RCP 6.0 (b) and RCP 8.5 (c) emission scenarios. The logistic output raster classified into five potential classes viz., very high potential $(>0.7 .5)$, high potential $(0.5-0.75)$, good potential $(0.25-$ $0.5)$, moderate potential $(0.13-0.25)$ and least potential $(<0.13)$ the distribution. The atmospheric $\mathrm{CO}_{2}$ concentration, temperature, or precipitation will directly affect metabolic and developmental rates in many animals (Hughes 2000). The reproductive requirements, habitat selection, and foraging patterns of bats may also have unequal effects due to changes in temperature (Sherwin et al. 2012). Latidens salimalii is a cave-dwelling species and is very sensitive to disturbances (Vanitharani et al. 2004) can be more influenced by the changing climate. The bats have specialised roosting types, specifically in cave and tree (Sherwin et al. 2012). At different stages of life-history, they may face significant risk when there is an alteration in vegetation and climate. According to the present projections, the twenty-first century will confront a quick climate change that could influence the distribution and diversity of climate specialist animals. The Intergovernmental Panel on Climate Change (IPCC) gauged a severe danger of termination for $20-30 \%$ of species with the ascent of $2-3{ }^{\circ} \mathrm{C}$ temperature globally (Stocker et al. 2013; Warren et al. 2013). Under the evolving climate, the atmospheric pressure alters (Shukla et al. 2003) over WG, which upsets the too delicate ecological balance accelerating the increased extinction of dependent fauna and change of floral composition.

A mutualistic dependency exists between native flora and the critically dependent frugivorous fauna. This association is crucial, as even a small imbalance can lead to the extermination of both the species (Jordano et al. 2011). Hence, any impact on the endemic or native flora is reflected by the extinction of the habitat specialist, either through climatic variation or other synthetic reasons. The fundamental inter-dependence is vital for numerous ecological processes. The co-evolution, interactions, colonization, and large-scale range dynamics, life-history, and seasonal changes in natural habitats seem related (Jordano et al. 2011). Many species respond to climate change by shifting their distribution pattern to suitable other habitats for existence (Mokany et al. 2013). The alteration in the climatic conditions determines the productivity as well as the presence of native highaltitude flora. Studies by Gopalakrishnan et al. (2011) and Chaturvedi et al. (2011), based on the vulnerability index, estimated that the WG is highly vulnerable to climate changes than the Northeastern forests. The modification of 
climate can adversely affect the regional water resources (Wagner and Weitzman 2015), thereby impacting local diversity unfavorably. Trophic structure alterations are visible from the climatically sensitive areas (Walther et al. 2002). The transformed climatic environments upset and prolong the growing seasons, which give an upper hand for the invasive or non-native species. The tropical montane habitats like WG hosts many threatened taxa with restricted distribution, which can be vulnerable to local extinction due to increased human footprint and spread of invasive species (Arasumani et al. 2019). The pace of spreading invasive species (flora and fauna) can be at a high rate in a changing environment, as they quickly occupy novel niches. The successful invaders are phenologically flexible species that inhabit regions where endemic species thrive (Moran and Alexander 2014). The exotic invader flora has identical characteristics of endemic flora and a synchronous dispersal pattern. The external factors like climatic forcing act as a significant factor in altering the trophic structure by replacement (Walther et al. 2002). Due to complex topography and biogeographic history, fragile montane ecosystems respond quickly to climate change (Sukumar et al. 1995).

The current study is the pioneer one to demonstrate the potential risk and anticipates climatic impact on the viability of $L$. salimalii. The reported threats to the species are hunting for medicinal value and timber logging (Molur and Vanitharani 2008). In the western slopes of the WG, after the outbreak of the Nippa epidemic and COVID 19 pandemic, bats in general, are facing threats from the local populace. Bats were reported as carriers of viruses for many emerging zoonotic diseases and closely related to the corona virus like SARS (Wang et al. 2006; Lau et al. 2020). Frugivorous bats host the Nippa virus (Yadav et al. 2012), and the virus is spreading through secretions. No zoonotic epidemic is recorded from the roosting regions of $L$. salimalii, as the human may not prefer to share the native berry fed by $L$. salimalii. The HSM on Nilgiritragus hylocrius (Sony et al. 2018), Herpestes fuscus fuscus (Raman et al. 2020), and Piper nigrum (Sen et al. 2016) also predict a complete loss of suitable habitats in the southern WG in the future emission scenario underlines the change of floral texture. This alteration on the indigenous faunal composition can be through the succession of exotics or resistive species over the native flora. The evolution of a new floral pattern is a threat to the endemic fauna-floral interaction dynamics that can lead to the culmination of reliant fauna. The transformation predicted for the $L$. salimalii, is a predictive picture for the changing trophic composition, indicating the changing floral design of the WG. Hence, we expect the southern WG is changing in the changing climatic scenario, contributed by a multitude of reasons.

In conclusion, global warming is a threat to climate specialist endemic fauna existing in the high altitude regions. These threats reach its summit with the changing land use and land cover patterns. The protection of $L$. salimalii in the changing climate scenario is probable only by protecting the native fragile ecosystem of WG anticipating the change in the climate. The study practically implies the conservation of the entire Western Ghats is by protecting its unique landscape, preservation of native flora, check on the exotic invasion and anthropogenic impediments. Intense surveys on the predicted habitat will help to locate more populations and comprehend the ecology of this lesser-known species. Understanding the people's perception, especially in the pandemic situation, creating awareness and involvement of the local community can engender better results towards conservation. We suggest exhaustive research on the ecobiology of this species to develop a suitable management plan encompassing the micro and macro variables to enrich habitat quality and quantity.

Acknowledgements We acknowledge the Kerala Forests and Wildlife Department, Ministry of Environment, Forest \& Climate Change (MoEF and CC), National Biodiversity Authority (NBA) for granting permits for fieldwork (Order \# WL10-14322/2017, 2018). We are grateful to Alice $\mathrm{C}$ Hughes and anonymous reviewers for valuable comments which significantly improved the quality of manuscript. We thank Akhil Padmarajan and Muhammed Faizal for assisting in the field.

Funding The first author received a project fund sponsored by UCAS scholarship for international students by the Chinese National Natural Science Foundation (Grant No. U1602265, Mapping Karst Biodiversity in Yunnan), the Strategic Priority Research Program of the Chinese Academy of Sciences (Grant \# XDA20050202), the West Light Talent Program of the Chinese Academy of Sciences (Grant \# Y9XB011B01), the Chinese Academy of Sciences Southeast Asia Biodiversity Research Center fund (Grant \# Y4ZK111B01) through Landscape Ecology Group, CIC, XTBG.

\section{References}

Agoramoorthy G, Hsu M (2005) Population size, feeding, forearm length, and bodyweight of a less known India fruit bat, Latidens salimalii. Curr Sci 88(3):354-356

Aiello-Lammens ME, Boria RA, Radosavljevic A, Vilela B, Anderson RP (2015) spThin: An R package for spatial thinning of species occurrence records for use in ecological niche models. Ecography 38:541-545

Allouche O, Tsoare A, Kadmon R (2006) Assessing the accuracy of species distribution models: prevalence, kappa and the true skill statistic (TSS). J Appl Ecol 43:1223-1232

Arasumani M, Khan D, Vishnudas CK, Muthukumar M, Milind B, Robin VV (2019) Invasion compounds an ecosystem-wide loss to afforestation in the tropical grasslands of the Shola Sky Islands. Biol Conserv 230:141-150

Austin M (2007) Species distribution models and ecological theory: a critical assessment and some possible new approaches. Ecol Modell 200:1-19

Babu S, Srinivas G, Kumara HN, Tamilarasu K, Molur S (2013) Mammals of the Meghamalai landscape, southern Western Ghats, India - a review. J Threat Taxa 5(15):4945-4952

Bates PJJ, Harrison DL (1997) Bats of the Indian Subcontinent. Harrison Zoological Museum Publications, Sevenoaks 
Bates PJJ, Harrison DL, Thomas NM, Muni M (1994) The Indian Fruit Bat Latidens salimalii Thonglongya, 1972(Chiroptera, Pteropodidae) rediscovered in southern India. Bonner Zool Beitr 45(2):89-98

Bellard C, Bertelsmeier C, Leadley P, Thuiller W, Courchamp F (2012) Impacts of climate change on the future of biodiversity. Ecol Lett 15:365-377

Bosso L, Smeraldo S, Rapuzzi P, Sama G, Garonna AP, Russo D (2018) Nature protection areas of Europe are insufficient to preserve the threatened beetle Rosalia alpina (Coleoptera: Cerambycidae): evidence from species distribution models and conservation gap analysis. Ecol Entomol 43(2):192-203

Bunyan M, Bardhan S, Jose S (2012) The shola (tropical montane forest)-grassland ecosystem mosaic of peninsular India: a review. Am J Plant Sci 3(11):1632

Castaño JH, Carranza JA, Pérez-Torres J (2018) Diet and trophic structure in assemblages of montane frugivorous phyllostomid bats. Acta Oecol 91:81-90

Chapman CA, Chapman LJ, Zanne AE, Poulsen JR, Clark CJ (2005) A12-year phenological record of fruiting: Implications for frugivore populations and indicators of climate change. In: Dew JL, Boubli JP (eds) Tropical fruits and frugivores: the search for strong interactors. Springer, Dordrecht, pp 75-92

Chaturvedi RK, Gopalakrishnan R, Jayaraman M, Bala G, Joshi NV, Sukumar R, Ravindranath NH (2011) Impact of climate change on Indian forests: a dynamic vegetation modelling approach. Curr Sci 90(3):354-361

Cincotta RP, Wisnewski J, Engelman R (2000) Human population in the biodiversity hotspots. Nature 404:990-992

Crowther TW, Glick HB, Covey KR, Bettigole C, Maynard DS, Thomas SM, Smith JR, Hintler G, Duguid MC, Amatulli G, Tuanmu MN, Jetz W, Salas C, Stam C, Piotto D, Tavani R, Green S, Bruce G, Williams SJ, Wiser SK, Huber MO, Hengeveld GM, Nabuurs GJ, Tikhonova E, Borchardt P, Li CF, Powrie LW, Fischer M, Hemp A, Homeier J, Cho P, Vibrans AC, Umunay PM, Piao SL, Rowe CW, Ashton MS, Crane PR, Bradford MA (2015) Mapping tree density at a global scale. Nature 525(7568):201-205

Debata S, Panda RM, Palita SK (2019) Chiropteran diversity and the key determinants of their distribution in Eastern Ghats, India. Biodivers Conserv 28:2385-2404

Easa PS, Zacharias J, Padmanabhan P (2001) Survey of small mammals in Kerala with special reference to endangered species and wildlife census in Chinnar Wildlife Sanctuary. KFRI Research Report No: 207

Ghosh MK, Bhattacharyya TP, Saha SS (1999) Occurrence of Salim Ali's Fruit Bat (Latidens salimalii Thonglongya, 1972) in the Kalakkad-Mundanthurai Tiger Reserve, Tamil Nadu. Tiger Paper 26(2):32

Gopalakrishnan R, Jayaraman M, Bala G, Ravindranath NH (2011) Climate change and Indian forests. Curr Sci 101(3):348-355

Hughes L (2000) Biological consequences of global warming: Is the signal already apparent? Trends Ecol Evol 15(2):56-61

Jordano P, Forget PM, Lambert JE, Böhning-Gaese K, Traveset A, Wright SJ (2011) Frugivores and seed dispersal: Mechanisms and consequences for biodiversity of a key ecological interaction. Biol Lett 7:321-323

Jose S, Sreepathy A, Kumar BM, Venugopal VK (1994) Structural, floristic and edaphic attributes of the grassland-shola forests of Eravikulam in peninsular India. For Ecol Manag 65(2-3):279-291

Joy TK, Vanitharani J, Jeyapraba L (2019) First Authentic Report of Salim Ali's Fruit Bat (Latidens salimalii) and its range extinction record in Kerala State of Southern Western Ghats. Ambient Sci 06(2):53-55

Lau S, Luk H, Wong A, Li K, Zh L, He Z, Chan T, Fung K, Woo P (2020) Possible bat origin of severe acute respiratory syndrome coronavirus 2. Emerg Infect Dis 26(7):1542-1547
Lobo JM, Jiménez-valverde A, Real R (2008) AUC: a misleading measure of the performance of predictive distribution models. Glob Ecol Biogeogr 17:145-151

Menon S, Bawa KS (1997) Applications of geographic information systems, remote-sensing, and a landscape ecology approach to biodiversity conservation in the Western Ghats. Curr Sci 73:134-145

Merow C, Smith MJ, Silander JA (2013) A practical guide to MaxEnt for modeling species' distributions: What it does, and why inputs and settings matter. Ecography 36:1058-1069

Mokany K, Harwood TD, Ferrier S (2013) Comparing habitat configuration strategies for retaining biodiversity under climate change. West Afr J Appl Ecol 50:519-527

Molur S, Vanitharani J (2008) Latidens salimalii. The IUCN red list of threatened species 2008. https://doi.org/10.2305/IUCN.UK.2008. RLTS.T11374A3274238.en

Molur S, Marimuthu G, Srinivasulu C, Mistry S, Hutson AM, Bates PJJ, Walker S, Priya KP, Binu-Priya AR (2002) Status of South Asian Chiroptera. Conservation action management plan (CAMP) Workshop Report. Zoo Outreach Organisation

Moran EV, Alexander JM (2014) Evolutionary responses to global change: lessons from invasive species. Ecol Lett 17(5):637-649

Muni M (1994) Rarest of the rare: Latidens salimalii. Hornbill 1:28-32

Muscarella R, Galante PJ, Soley-Guardia M, Boria RA, Kass JM, Uriarte M, Anderson RP (2014) ENM eval: an R package for conducting spatially independent evaluations and estimating optimal model complexity for Maxent ecological niche models. Methods Ecol Evol 5(11):1198-1205

Myers N, Mittermeler RA, Mittermeler CG et al (2000) biodiversity hotspots for conservation priorities. Nature 403:853-858

Naimi B (2013) USDM: uncertainty analysis for species distribution models. R Package version, pp 1 1-12. https://cran.r-project.org/ web/packages/usdm/usdm.pdf

Phillips SJ, Anderson RP, Schapire RE (2006) Maximum entropy modeling of species geographic distributions. Ecol Modell 190:231-259

Priti H, Aravind NA, Uma Shaanker R, Ravikanth G (2016) Modeling impacts of future climate on the distribution of Myristicaceae species in the Western Ghats, India. Ecol Eng 89:14-23

Raman S, Shameer TT, Sanil R, Usha P, Kumar S (2020) Protrusive influence of climate change on the ecological niche of endemic brown mongoose (Herpestes fuscus fuscus): a MaxEnt approach from Western Ghats, India. MESE 6:1795-1806

RameshKumar MR, Shenoi SC, Shankar D (2004) Monsoon onset over Kerala and pre monsoon rainfall peak. In: Proceedings of the National Symposium METOC-2004 on Emerging Trends in the Fields of Oceanography and Meteorology, NIO, pp 305-307

Sen S, Gode A, Ramanujam S, Ravikanth G, Aravind NA (2016) Modeling the impact of climate change on wild Piper nigrum (Black Pepper) in Western Ghats, India using ecological niche models. Int J Plant Res 129:1033-1040

Sharma J, Upgupta S, Jayaraman M, Chaturvedi RK, Bala G, Ravindranath NH (2017) Vulnerability of forests in India: a national scale assessment. Environ Manage 60:544-553

Sherwin HA, Montgomery WI, Lundy MG (2012) The impact and implications of climate change for bats. Mamm Rev 43:171-182

Shukla PR, Sharma SK, Ravindranath NH, Garg A, Bhattacharya S (2003) Climate change and India: vulnerability assessment and adaptation. Universities Press, Hyderabad

Sikes RS, Gannon WL (2011) the animal care and use committee of the American society of mammalogists. Guidelines of the American Society of Mammalogists for the use of wild mammals in research. J Mamm 92:235-253 
Simard M, Pinto N, Fisher JB, Baccini A (2011) Mapping forest canopy height globally with spaceborne lidar. J Geophys Res Biogeosci 116:G04021

Singaravelan N, Marimuthu G (2003a) Mist net captures of the rarest fruit bat Latidens salimalii. Curr Sci 84(1):101-103

Singaravelan N, Marimuthu G (2003b) Discovery of a cave as the day roost of a rarest fruit bat Latidens salimalii. Curr Sci 84:1253-1256

Sony RK, Sen S, Kumar S (2018) Niche models inform the effects of climate change on the endangered Nilgiri Tahr (Nilgiritragus hylocrius) populations in the southern Western Ghats, India. Ecol Eng 120:355-363

Soucy JPR, Andreea MS, Christine N, Nicholas HO, Patrick AL, Jeremy TK, Manisha AK (2018) High-resolution ecological niche modeling of Ixodes scapularis ticks based on passive surveillance data at the northern frontier of Lyme disease emergence in North America. Vector Borne Zoonotic Dis 18(5):235-242

Sousa-Guedes D, Arenas-Castro S, Sillero N (2020) Ecological Niche models reveal climate change effect on biogeographical regions: the Iberian Peninsula as a case study. Climate 8:42

Stocker TF, Qin D, Plattner G-K et al (2013) Technical summary. In: Stocker TF, Qin D, Plattner G-K, et al. (eds) Climate change 2013: the physical science basis Contribution of Working Group I to the Fifth Assessment Report of the Intergovernmental Panel on climate change. Cambridge University Press, Cambridge, pp 33-115

Sukumar R, Suresh HS, Ramesh R (1995) Climate change and its impact on tropical montane ecosystems in Southern India. J Biogeogr 22(2/3):533-536

Thonglongya K (1972) A new genus and species of fruit bat from South India (Chiroptera: Pteropodidae). J Bombay Nat Hist Soc 69(1):151-158

Vanitharani J, Pearch M, Praba LJ, Annamalai R (2004) A review of the distribution and status of Latidens salimalii (Chiroptera:
Pteropodidae) with new records from the Western Ghats, India. Lutra 47(1):21-32

Veloz SD (2009) Spatially autocorrelated sampling falsely inflates measures of accuracy for presence-only niche models. J Biogeogr 36(12):2290-2299

Vijayakumar SP, Menezes RC, Jayarajan A, Shanker K (2016) Glaciations, gradients, and geography: multiple drivers of diversification of bush frogs in the Western Ghats Escarpment. Proc R Soc B Biol Sci 283(1836):20161011

Wagner G, Weitzman ML (2015) Climate shock: the economic consequences of a hotter planet. Princeton University Press, Princeton

Walther GR, Post E, Convey P, Menzel A, Parmesan C, Beebee TJC, Fromentin J, Hoegh-Guldberg O, Bairlein F (2002) Ecological responses to recent climate change. Nature 416:389-395

Wand MP (1994) Fast computation of multivariate kernel estimators. J Comput Graph Stat 3:433-445

Wang LF, Shi Z, Zhang S, Field H, Daszak P, Eaton BT (2006) Review of bats and SARS. Emerg Infect Dis 12(12):1834-1840

Warren R, VanDerWal J, Price J, Welbergen JA, Atkinson I, RamirezVillegas J, Osborn TJ, Jarvis A, Shoo LP, Williams SE, Lowe J (2013) Quantifying the benefit of early climate change mitigation in avoiding biodiversity loss. Nat Clim Change 3:678-682

Wordley CF, Foui EK, Mudappa D, Sankaran M, Altringham JD (2016) Range extension of the endangered Salim Ali Fruit Bat Latidens salimalii (Chiroptera: Pteropodidae) in the Anamalai Hills, Tamil Nadu, India. J Threat Taxa 8(12):9486-9490

Yadav PD, Raut CG, Shete AM, Mishra AC, Towner JS, Nichol ST, Mourya DT (2012) Detection of Nipah virus RNA in fruit bat (Pteropus giganteus) from India. Am J Trop Med Hyg 87(3):576-578

Zhang K, Yao L, Meng J, Tao J (2018) Maxent modeling for predicting the potential geographical distribution of two peony species under climate change. Sci Total Environ 634:1326-1334 